\title{
Repensar el objeto fotográfico: un acercamiento desde la teoría del afecto
}

\author{
Sandra Peña Haro*
}

Artículo recibido:

4 de junio de 2021

Artículo aceptado:

22 de septiembre de 2021

Artículo de investigación

\section{Resumen}

El presente trabajo profundiza en los rasgos afectivos que se imprimen en el objeto fotográfico, así como en las colecciones a las que se integran en su devenir en el tiempo. En este sentido, recurre a las herramientas del llamado "giro afectivo" para abrir una reflexión sobre las posibilidades del objeto fotográfico y los acervos, a fin de identificar elementos que amplíen el horizonte informativo que se utiliza en el procesamiento de las colecciones en los repositorios. El ejercicio se centra en analizar dos fotografías del Fondo Aurelio Robles Acevedo, que resguarda el Archivo Histórico de la Universidad Nacional Autónoma de México, a la luz de la

\footnotetext{
Instituto de Investigaciones sobre la Universidad y la Educación, Universidad Nacional Autónoma de México, México

sandra.pena.haro@comunidad.unam.mx INVESTIGACIÓN BIBLIOTECOLÓGICA, vol.36, núm. 90, enero/marzo, 2022, México, ISSN: 2448-8321 pp. 87-100
} 
propuesta teórica de Ann Cvetkovich en An Archive of Feelings y de Sara Ahmed en La política cultural de las emociones, quienes estudian los acervos desde perspectivas teóricas ligeramente distanciadas que los identifican como textos culturales receptores de sentimientos codificados en el contenido, o bien, como "una zona de contacto" que incluye impresiones de naturaleza personal e institucional.

Palabras clave: Afecto; Acervo; Fotografía; Conservación

Rethinking the photographic object, an approach from the Affect Theory

Sandra Peña Haro

\section{Abstract}

The present work explores the affective features that are imprinted on the photographic object, as well as on the collections which they are integrated to in its evolution over time. In this framework, it nourishes from the tools of the "affective turn" to open an analysis of the photographic object to identify elements that broaden the information horizon, which is used in arranging and conserving collections in repositories. The exercise focuses on two photographs of the Aurelio Robles Acevedo Fond that keeps the Historical Archive of the National Autonomous University of Mexico and analyses them considering the proposal of Ann Cvetkovich in An Archive of Feelings and of Sara Ahmed in The Cultural Politics of Emotion, which insist on studying archives from slightly distanced perspectives that identify them as cultural texts receiving feelings encoded in the content or, like a "contact zone" that includes imprints of institutional and personal nature.

Keywords: Affect; Heritage; Photography; Conservation 


\section{INTRODUCCIÓN}

D esde el siglo XIX la fotografía ha desempeñado un papel de primer orden en la construcción de narrativas en virtud de que ayuda a fortalecer el sentido de identidad y pertenencia. Esto hace evidente el papel social que ejerce como un elemento legitimador de las creencias particulares. Cabe recordar que las naciones y comunidades se definen a sí mismas a través de actos simbólicos e imaginativos que dan cuenta de una autopercepción que se afirma y sedimenta por la vía de las imágenes, mezclando rasgos probatorios de carácter moral y afectivo (Edwards, 2015: 322).

Elizabeth Edwards señala que las imágenes, por su potencial de certeza, actúan como "signos vitales" los cuales operan en el ámbito emocional para crear un sentido de identidad y pertenencia (2015: 322). En consecuencia, rebasan las declaraciones intrínsecas que traen consigo asentándose en las posibilidades simbólicas, así como afectivas, las cuales provienen de la identidad cultural de las comunidades (Bhabha, 1994: 201). Así pues, la imagen constituye un elemento crucial en la construcción de narrativas, por ejemplo, las que emanan del Estado, y las llamadas contranarrativas, que por distintos medios buscan su inserción en el discurso histórico. En ambos casos se trata de construcciones discursivas estables elaboradas a partir de la interacción que establecen los sujetos entre sí y con los objetos (Latour, 2008: 19; Muriel, 2013: 35-37).

En este contexto, la famosa pregunta que formuló el especialista en el estudio de la fotografía W. J. T. Mitchell, en su obra What do pictures want?, la usó Elizabeth Edwards para esclarecer la relación existente entre las imágenes y los sujetos. En la práctica esta premisa ayudó a reformular el cuestionamiento desde la perspectiva del sujeto y su enunciación como "what do people want pictures to be?," que permitió a la autora incursionar en el potencial de las fotografías como una vía para generar un "tejido conectivo", el cual vincula a las personas entre sí con lugares o momentos (Edwards, 2015: 324).

El presente texto abunda, en efecto, en el análisis de las nuevas interpretaciones en torno a la fotografía que subrayan su potencial afectivo, así como su papel en la construcción y transmisión identitaria de los grupos; todo ello en el entendido de que la última característica se erige como uno de los rasgos más representativos e importantes de las colecciones y archivos personales que deben ser considerados durante el procesamiento técnico. 
Con este ánimo se revisan algunas fotografías que forman parte del Fondo Aurelio Robles Acevedo (Fondo ARA), ${ }_{1}$ considerando la propuesta que elaboró Ann Cvetkovich en su trabajo An Archive of Feelings, que sugiere analizar las fotografías como "textos culturales receptores de sentimientos y emociones que se localizan codificados en el contenido del texto, así como en las prácticas de producción y recepción" (2003: 220). De igual forma, el análisis se apoya en el texto La política cultural de las emociones, en el que Sara Ahmed afirma que las emociones toman forma a partir del contacto entre sujeto y objeto (2015: 27).

Cabe precisar que las fotografías en cuestión fueron donadas al Archivo Histórico de la UNAM (AHUNAM) el 13 de junio de 1985, y quedaron bajo la custodia del Centro de Estudios sobre la Universidad (CESU), hoy Instituto de Investigaciones sobre la Universidad y la Educación (IISUE). El acuerdo permitió el ingreso de 10.7 metros lineales de documentos y 1922 imágenes que forman parte de la memoria de los grupos cristeros que se opusieron a la política anticlerical de los gobiernos postrevolucionarios. Las imágenes que se analizan forman parte de un grupo de 700 fotografías que retratan a los cristeros que participaron en dos momentos de la rebelión, de 1926 a 1929 y de 1935 a 1939.

\section{IMPRESIONES AFECTIVAS EN EL OBJETO FOTOGRÁFICO}

Una forma de profundizar en la teoría del afecto en los acervos es, como se anunció, revisar los trabajos que abrieron esta corriente de interpretación en este ámbito en particular. Por ejemplo, Ann Cvetkovich advierte que los materiales documentales son una suerte de repositorios codificados de sentimientos y emociones en su contenido y prácticas que rodean su producción y recepción (Cifor, 2016: 15). En su trabajo titulado An Archive of Feelings: Trauma, Sexuality and Lesbian Public Cultures, la autora propone el concepto de trauma como una experiencia socialmente situada que genera "presión en las formas convencionales de documentación, representación y conmemoración. Todas ellas generan distintas formas de expresión testimonial que se traducen en nuevas representaciones de monumentos, rituales y actos performativos" (Cvetkovich, 2003: 220). Afirma que el trauma se inserta en la

1 Aurelio Robles Acevedo nació el 25 de julio de 1900 en el municipio de Valparaíso, Zacatecas, y participó en la gesta en el regimiento cristero de Pedro Quintanar, donde alcanzó el grado de general brigadier de los regimientos de Valparaíso, Libres de Huejuquilla, Libres de Chal- 
narrativa y en los artefactos materiales como las fotografías imprimiendo un valor emocional y sentimental (2003: 214).

Por otra parte, Sara Ahmed, en su trabajo La política cultural de las emociones, señala, como mencionamos antes, que las emociones no residen en el sujeto o el objeto, sino que tomarán forma en la medida en que ambos entran en contacto (2015: 27). Profundiza en la forma en la cual las emociones moldean las "superficies de los cuerpos individuales y colectivos" a través de una impresión cuyo término recupera del trabajo de David Hume sobre la emoción (Ahmed, 2015: 312). De igual forma, recurre al vocablo impresión para evitar las distinciones entre "sensación corporal, emoción y pensamiento", ya que advierte que se experimentan en un mismo ámbito a través de un proceso recíproco en el cual "el objeto de sentimiento moldea y es moldeado a la vez por las emociones” (Ahmed, 2015: 28).

Bajo este espectro, el afecto es una fuerza que crea una relación entre el cuerpo y el mundo: se localiza en el corazón y se hace evidente en cómo formamos, sostenemos y rompemos relaciones sociales, así como en la forma en la cual establecemos diferencias y consolidamos las identidades individuales y colectivas (Cifor, 2016: 8). Por ejemplo, Marika Cifor advierte que los archivos subrayan la creación, documentación, mantenimiento, reconciliación y (re)producción de las relaciones -entre documentos y personas, ideologías, instituciones, sistemas y palabras- a través de las fronteras del tiempo y el espacio. En suma, la teoría del afecto proporciona argumentos para desafiar y reconceptualizar las funciones y el ámbito de trabajo de los acervos documentales (2016: 8).

Cabe afirmar que el afecto es en sí mismo una categoría que se construye en el ámbito cultural, social e histórico, aunque se extiende y rebasa el campo de los sentimientos y las emociones. Se trata de una propuesta que amplía las posibilidades de investigación e incluso llega a extender los límites de lo cognitivo y lo narrativo. De esta forma, las herramientas metodológicas que el "giro afectivo" proporciona facilitan el abordaje de problemas cruciales de (in)justicia y poder, e incluyen al archivo desde una perspectiva social en temas como la identidad, el cuerpo, la memoria colectiva y el empoderamiento de la comunidad (Cifor, 2016: 10).

La autora insiste de forma concisa en las razones que explican el interés tangencial de la teoría del afecto en el ámbito disciplinar de los archivos, a sabiendas de que procede de la fundamentación de la práctica y teoría como un ejercicio "científico" centrado en la objetividad y en el ideal de neutralidad. Aunque con la salvedad de que si bien los profesionales de los acervos reconocen los signos como portadores de significados, dejan fuera la forma en que los objetos y la relación con sus portadores están mediadas por el afecto (Cifor, 2016: 11-12). 
Ahora bien, con el ánimo de identificar los rasgos afectivos que se imprimen en las fotografías, en este apartado se analizan dos ejemplos concretos del Fondo Aurelio Robles Acevedo. El ejercicio implica recurrir a las ideas de Sara Ahmed, quien sugiere una lectura minuciosa de los textos subrayando las figuras de metonimia y metáfora que se adaptarán a las imágenes a fin de describir cómo se generan los afectos, sin olvidar que la autora afirma que las emociones se acumulan como una carga de valor afectivo que se deposita en los objetos ante la eliminación de la historia de su producción y circulación (2015: 37). Así, advierte que el análisis debe concentrarse no sólo en la imagen sino también en la "emocionalidad", la cual remite a la forma en que se generan y mueven los afectos, pues subraya la necesidad de reflexionar en "cómo trabajan los materiales a través de las emociones para generar efectos" (Ahmed, 2015: 39). Insiste en que para rastrear los depósitos de afecto es necesario analizar el contenido e incursionar en el origen, así como en las formas de transmisión del objeto fotográfico. Con este fin, se hace una breve revisión de la imagen y los textos que la acompañan para rastrear las huellas que han dejado las historias en el devenir de la fotografía y, por lo tanto, la naturaleza de la impresión que se produce en el individuo que se acerca a ellas (Ahmed, 2015: 31).

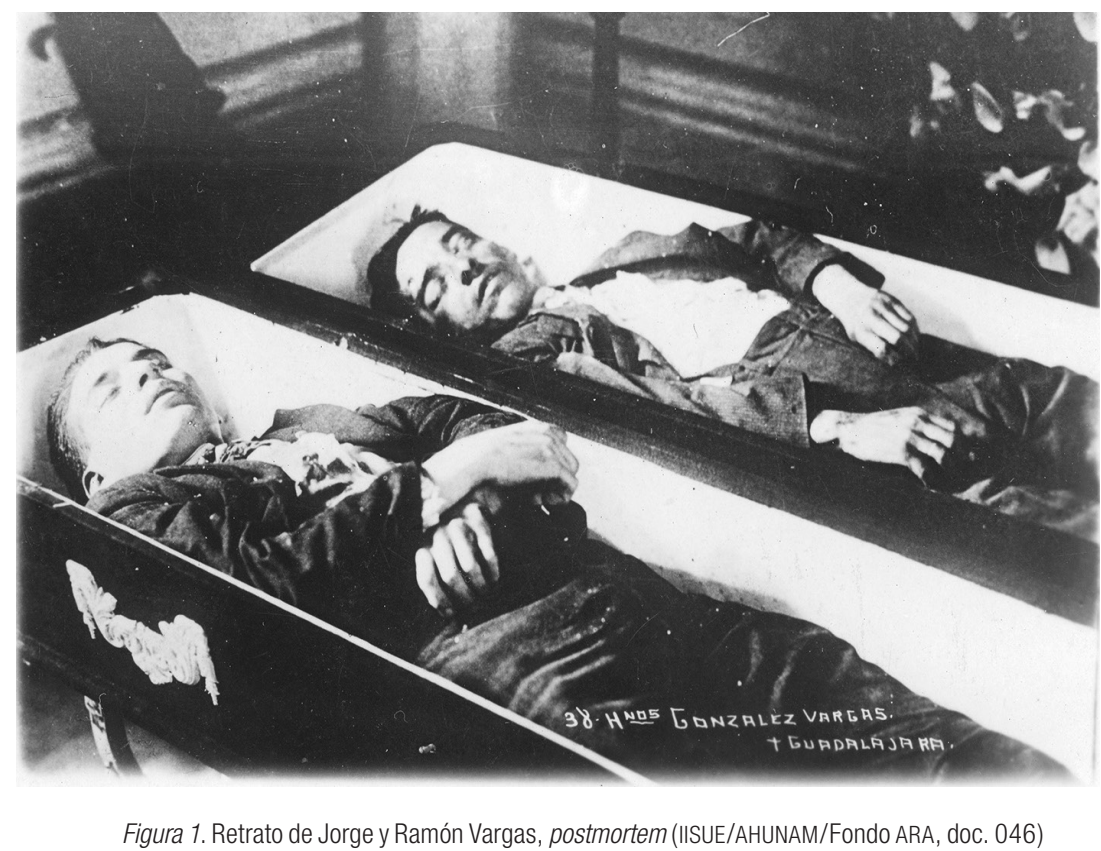


Un primer ejemplo de este ejercicio es la fotografía postmortem de Jorge y Ramón Vargas González, que en la memoria cristera fue elegida, preservada y transmitida por un núcleo cercano a los hermanos. El interés por transmitir esta imagen fue registrar el martirio de ambos cristeros y colocarla en el martirologio mexicano que sería rescatado por el pontificado del papa Benedicto XVI en noviembre de 2005.

Respecto de la intención de subrayar el martirio cristero de los hermanos Vargas, en el Fondo ARA hay tres imágenes más: las del cortejo fúnebre que acompañó a Anacleto González y los hermanos Vargas en Guadalajara, el 1 de abril de 1927,2 y un par de impresos de origen español titulados "Mártires de Guadalajara". ${ }^{3}$ Cabe precisar que el fondo no incluye fotografías de Florentino Vargas, quien también fue capturado en dicha ocasión pero fue liberado por equivocación en el Cuartel Colorado de Guadalajara. En efecto, un soldado preguntó por el más joven de los tres hermanos a fin de separarlo del cuadro, y se dice que Ramón (el menor) le dijo a Florentino: "levántate tú, Narciso (así le decía de cariño)," circunstancia que lo libró de morir en el paredón junto a sus hermanos, que serían ejecutados momentos después (Enciclopedia, s. a.: 18).

Sin duda, la imagen constata el sacrificio, tortura y fusilamiento del cual fueron objeto los hermanos a manos del ejército, aunque las crónicas orales conservaron a detalle elementos del martirio subrayando la devoción católica de ambos. Por ejemplo, destacan que el cadáver de Jorge llevaba un crucifijo en el pecho, el cual sostuvo al recibir las descargas de los fusiles; por otra parte, se afirma que Ramón conservó la señal de la cruz en la mano derecha (Vaticano, s. a.: párr. 21). Una de las crónicas que más impresionan en este suceso quedó plasmada en la nota al reverso de una de las fotografías de la velación de los cuerpos de los hermanos asesinados y que ofrece la reacción de la madre de Florentino Vargas a su regreso a casa:

Fueron aprehendidos junto con Anacleto González tres hermanos González Vargas. El menor de ellos fue indultado. Por un error del militar que separó del cuadro de la ejecución al que creía menor, separó al de en medio. Cuando regresó éste con los dos cadáveres de Jorge y de Salvador a la casa recién abandonada, la madre de los mártires se acercó al hijo que le quedaba diciéndole: "Ay, hijito, qué cerca estubo [sic] de ti la corona y no la alcanzaste. Necesitas ser más bueno para merecerla". (IISUE/AHUNAM/Fondo ARA, doc. 46)

2 Veánse los documentos IISUE/AHUNAM/Fondo ARA 132, 133 y 134.

3 Veánse los documentos IISUE/AHUNAM/Fondo ARA 1814 y 1840. 
El texto asociado a la imagen otorgó al sacrificio de los hermanos una nueva dimensión, pues la impresión del núcleo familiar se extendió a la comunidad cristera que incluso pervive en el lector actual. Así, el lector/participante es afectado en función de las historias que permanecen vivas -o no- en su contexto produciendo efectos particulares en función de sus creencias (Ahmed, 2015: 31). Experimenta, por lo tanto, emociones que pueden resultar encontradas si el lector se identifica con la comunidad cristera o se ubica fuera de ella.

Las fotografías, en efecto, no sólo son imágenes sino objetos provistos de una existencia espacial y temporal que de manera irremediable están impregnados de experiencias de naturaleza social y cultural (Edwards y Hart, 2005a: 1). Se trata de objetos cuyo devenir está influenciado por interacciones de naturaleza subjetiva y sensorial que no pueden ser reducidas a su existencia material ni a los símbolos o significados presentes en la imagen. El análisis debe considerar, por consiguiente, las decisiones de naturaleza afectiva que responden a asociaciones que surgen a través de la relación de las cosas y los humanos con las que están asociados (Edwards y Hart, 2005a: 6). La materialidad del objeto fotográfico, en efecto, está permeada de diversas experiencias que incorporan notas afectivas derivadas de su uso e intercambio (Edwards y Hart, 2005a: 13). Con relación a este punto, la Figura 2 ofrece el montaje de Carmen de Robles, ubicada en el centro de la fila delantera del grupo de mujeres católicas que fueron detenidas en Huejuquilla, Jalisco, el 17 de enero de 1928.

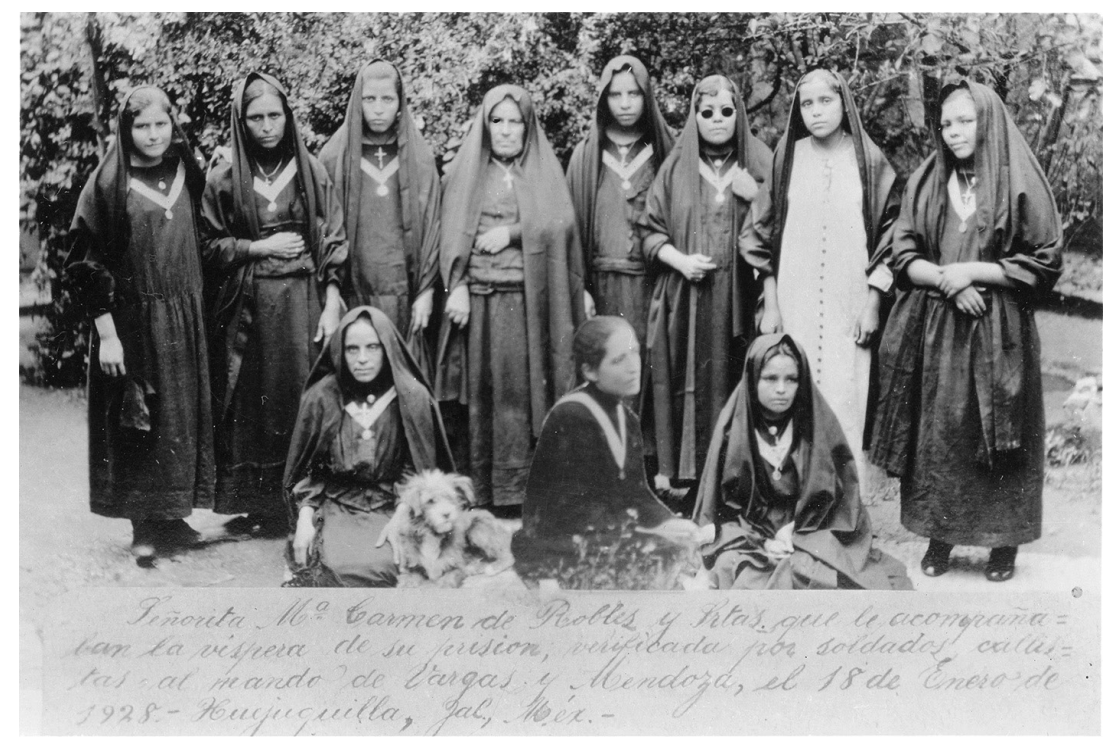

Figura 2. Fotografía con la imagen de Carmen de Robles incluida en el centro de la composición (IISUE/AHUNAM/Fondo ARA, doc. 679) 
La inscripción al pie de la imagen proporciona algunos datos sobre la aprehensión de la "Señorita Ma. Carmen de Robles y Sritas que le acompañaban la víspera de su prisión, verificada por soldados callistas al mando de Vargas y Mendoza, el 18 de enero de 1928.- Huejuquilla, Jal., Mex." (Acevedo, 2011: 21). Una mirada atenta a la imagen advertirá que ésta no incluía originalmente a Carmen de Robles, lo cual lleva a pensar que desde el momento de la toma se dejó un espacio para su posterior incorporación. Sin duda, la fotografía responde a un deseo de conservar la memoria de Carmen de Robles y del grupo de mujeres católicas que la acompañaron: Concha Ruiz, Hilaria Caldera, Margarita Victorio, Ignacia Ibarra, Carolina Ibarra, María Isabel Jaime y su hija Ramona. El ejército las acusó falsamente de ser monjas, así que fueron apresadas y llevadas a pie al pueblo de Mezquitic, en donde Carmen desapareció la noche del martes 17 de enero de 1928 (Acevedo, 2011: 21). Después, en 1963, se comprobó que ahí fue asesinada y sepultada (Arquidiócesis, 2009).

Cabe precisar que la imagen sólo será comprendida en tanto se tenga en cuenta la intención de su creación, lo cual rebasa el valor testimonial y la representación fidedigna de los hechos situándose en el ámbito de la memoria, así como en la resistencia al olvido de los mártires de Huejuquilla. Las características de esta fotografía muestran una decisión consciente que está presente en su propia conformación, pues registra la intervención de los participantes en el recuadro, la distancia y ángulo de registro que marcaron el devenir del objeto fotográfico.

Después del registro es indispensable mantener las cadenas de asociación de sujetos y objetos, que según Glenn Willumson continúan en lo que llamó la posibilidad de "redención o rechazo". Afirma que ésta tiene lugar en el ámbito doméstico, el cual es el espacio responsable de la pérdida o supresión de las fotografías menos relevantes. Sin embargo, conserva las que se consideran como "intensamente personales y repletas de memoria" (2005: 66). Ahora bien, esto se puede apreciar en la fotografía de los hermanos Vargas (Figura 1) o en el montaje de Carmen de Robles (Figura 2), que trascendieron ante el interés de la comunidad por preservar su memoria.

Las fotografías forman parte de una cadena de asociaciones que, en efecto, inciden de manera directa en su conformación como objeto y en la construcción discursiva del grupo de objetos, pues experimentan algunos cambios como la integración de la nota al reverso de la imagen de los hermanos Vargas o la incorporación de la imagen de Carmen de Robles. ${ }^{4}$ Se hace evidente que el

4 De acuerdo con Bruno Latour, la actuación de los objetos en el ámbito social debe considerar la sucesión de manos que la transmiten y las transformaciones que experimenta a lo largo del camino (Latour, 2008: 111-112). 
objeto fotográfico y el sentimiento son moldeados de manera recíproca en un proceso de co-construcción que deja impresiones derivadas de historias y afectos que continúan activándose. Dichos rasgos impresionan al lector de diferentes maneras en las cuales incide su posición en el mundo (Ahmed, 2015:31).

En este sentido, Sara Ahmed señala que "los sentimientos se pueden pegar a ciertos objetos y resbalarse a través de otros," lo cual es un fenómeno que se advierte en el vínculo construido entre los portadores y el objeto que ostenta la imagen más cercana al original o al acontecimiento (Ahmed, 2015: 31). En el grupo de imágenes del Fondo ARA, en efecto, es patente el interés de los familiares por conservar la fotografía original y ceder una copia. ${ }^{5}$ Todo ello confirma que aún la más exacta de las reproducciones deja afuera "la historia a la que ha estado sometida en el curso de su perduración" (Benjamin, 1989: 20).

\section{SUSPENSIÓN DE SIGNIFICADO DEL OBJETO FOTOGRÁFICO}

La incorporación de los grupos documentales a acervos institucionales, sin duda, provoca que la existencia singular de cada objeto fotográfico se vea reducida para insertarse en un contexto narrativo específico, pues con el ingreso serán receptores de un sentido y orden impuesto en el trabajo de procesamiento. Todo ello propicia la creación de un sentido intelectual y físico que obedece a reglas provenientes de la archivística, bibliotecología o las ciencias de la información, diseñadas para el procesamiento de documentación de conformidad con una serie de reglas preestablecidas.

Por ejemplo, Allan Sekula señala que este tipo de repositorios funcionan como un espacio de resignificación que identifica como "clearing house of meaning", en el cual las posibilidades de contenido originales son liberadas e impregnadas de la pérdida "de la complejidad y la riqueza que deviene con su uso" (2003: 445). Afirma que el procesamiento técnico de los grupos de fotografías propicia la suspensión del significado de uso, aunque el sentido original de las fotografías se preserva sólo de forma "residual y potencial" pues constituyen "en sí mismas, enunciados fragmentarios e incompletos" los cuales dependen del contexto que les fue eliminado (Sekula, 2003: 445).

La aplicación del proceso descrito en el caso de las fotografías del Fondo ARA advierte que el procesamiento archivístico que integra las imágenes a un acervo organizado, descrito y digitalizado bajo criterios homogéneos

5 Cabe señalar que todas las fotografías que conserva el Fondo ARA sobre la rebelión cristera son copias. 
modificó la visión original de su compilador. Así pues, durante el proceso de consulta a través de instrumentos de descripción o en bases de imágenes en línea es evidente que se subraya el valor informativo y se ocultan o suspenden otros atributos como la emocionalidad. ${ }^{6}$ Los archivos, en este sentido, propician un fenómeno que Sekula denomina "equivalencia visual abstracta" (2003: 445), el cual se ve potenciado con el acceso remoto que permite recuperar imágenes de contextos distintos en una misma búsqueda.

Con todo, en la gestión de las imágenes del Fondo ARA se puede establecer el origen de sus fuentes, así como de sus propósitos. De estos últimos, uno es el carácter familiar a sabiendas de la carga emotiva manifestada en el interés por la preservación de los registros de los participantes de la familia y de la comunidad cristera. Otro es el interés de registrar los acontecimientos que en este caso particular están determinados por las medidas promovidas por los gobiernos de la postrevolución. Ambas categorías no se excluyen, pues como afirma Sekula: "ninguna fotografía familiar logra crear un paraíso de sentimiento" ni existen imágenes comisionadas que no toquen la "estética del poder" (2003: 450-451).

Por consiguiente, es necesario identificar en el objeto fotográfico los rasgos del contexto que aún se conservan y considerar la posibilidad de incorporarlos en el procesamiento técnico. De igual forma, la naturaleza de su conformación que define al grupo para respetar el discurso que brinda en su disposición específica. Todo ello obliga a tener presente que las fotografías se integran en una agrupación de elementos, divididos y conectados entre sí a través de un mecanismo social que las recupera de un flujo de memorias que se ve notoriamente disminuido en su ingreso institucional.

\section{Conclusiones}

Un grupo documental está conformado, como vimos, por elementos de diferentes microhistorias que pueden ser descifradas, por ejemplo, a través de huellas: manchas, abrasiones, perforaciones e inscripciones visibles en la superficie del objeto fotográfico. Así, el uso de cualquier objeto puede ser rastreado a través de estas impresiones, las cuales se originan en su interacción con los sujetos y el medio. Las fotografías no son la excepción, pues se doblan, manchan, rompen y desvanecen a lo largo de su devenir en un proceso que de

6 Al respecto, véanse las imágenes de los integrantes de la Liga Nacional Defensora de la Libertad Religiosa (a partir de la 046) en la siguiente dirección (fecha de consulta: 4 de junio de 2021): http://www.ahunam.unam.mx/images/albums/3.1/album/01\%20Asociacion\%20Catolica $\% 20$ de\%20la\%20Juventud\%20ACJM/index.html\#ARA-0046.jpg 
forma paulatina modifica la morfología del objeto. Cada una de estas alteraciones se integra al objeto y participa en la construcción de un vínculo entre el pasado y el presente y, por supuesto, entre los sujetos a través del tiempo.

La memoria depositada en las fotografías es evidente que la propicia la persona a través de la manipulación cotidiana y también en actividades conscientes o incluso en la conservación o destrucción intencional. Por consiguiente, los objetos experimentan un proceso de revisión y reinterpretación constante en la construcción de la memoria, el cual produce alteraciones en su morfología y conformación. Estos cambios no necesariamente deben enunciarse como deterioros a sabiendas de que no participan en el devenir a un peor estado o condición como lo advierte el uso del término, pues son agentes activos en la construcción de la memoria los cuales pueden estar relacionados con su valor afectivo.

Ahora bien, en el presente texto se subrayó la participación de los objetos en la construcción de la memoria los cuales se pueden establecer en varios niveles, aunque hizo un énfasis particular en dos de ellos. En efecto, el primero advierte que, como resultado del uso e intercambio en el tiempo, la integración de las huellas e impresiones en la morfología del objeto fotográfico son visibles en forma de capas de significado. El segundo nivel es el que integra la construcción y reconstrucción de la memoria de una colección a través de la elaboración de una narrativa permeada de emociones y, por supuesto, de olvidos. De esta forma, los grupos documentales se crean como estabilizaciones materiales de los sujetos con la intención de "dar sentido al mundo, y a sí mismos en este mundo" (Zylinska, 2010: 144).

Es indispensable, pues, reconocer a los objetos fotográficos y grupos a los cuales se integran como el producto de un momento específico, así como destacar la importancia de la práctica de organizar, guardar y usar documentos. Esto impone tener presente que las características de las imágenes dependen en gran medida de su función y, por lo tanto, de la identificación del papel que desempeñaron, el mensaje que quieren transmitir, así como la forma en que fueron utilizadas en la vida diaria. Todo ello exige profundizar en las características de los objetos fotográficos e identificar sus múltiples facetas, en particular las que trascienden la frontera de su contenido informativo y que dan cuenta del uso y devenir a lo largo del tiempo.

Ahora bien, y más allá de la ponderación teórica sostenida en el texto, es fundamental reconocer que el procesamiento técnico de las fotografías está acompañado de la impresión de rasgos particulares en el objeto y el grupo en el cual se inserta. De igual forma, los procesos de organización, descripción, digitalización y, claro está, la conservación y restauración, incorporan elementos de un contexto reciente el cual no está integrado a la colección. 
Por consiguiente, es deseable que las actividades que se llevan a cabo en su procesamiento consideren las múltiples facetas que forman parte de las imágenes, así como las características que han adquirido y, por último, los significados que han acumulado en su devenir en el tiempo.

Una reflexión final que se desprende del abordaje realizado en el trabajo es que abre la posibilidad de adentrarse en las nuevas corrientes de interpretación en torno a la imagen que pueden incorporar el valor afectivo, pues insisten en considerar el aporte que ofrecen en el manejo y lectura de los grupos documentales. En efecto, la propuesta extiende el margen de análisis, el cual pondera el potencial afectivo implícito en el devenir de las configuraciones a las que se integran las imágenes. La contribución de esta corriente aplicada a los archivos fotográficos, sin duda, abre una ventana de investigación original que ayudaría a elaborar interrogantes interesantes en el estudio y procesamiento de las imágenes fotográficas cuyo campo necesita explorar caminos distintos a fin de enriquecer la función y el papel del objeto fotográfico.

\section{REFERENCIAS}

Acevedo, Cristóbal. 2011. Narraciones autobiográficas de Aurelio Acevedo Robles (ARA). Tomo II. Guadalajara: Amateditorial.

Ahmed, Sara. 2015. La política cultural de las emociones. México: Programa Universitario de Estudios de Género, Universidad Nacional Autónoma de México.

Arquidiócesis de Guadalajara. 2009. "Carmelita Robles, Mártir de Cristo de Mezquitic, Jalisco”, en Boletín Eclesiástico CXX (8). https://arquidiocesisgdl.org/boletin/2009-8-9.php

Benjamin, Walter. 1989. "La obra de arte en la época de su reproductibilidad técnica”, en Discursos Interrumpidos I, 16-59. Madrid: Taurus.

Bhabha, Homi. 1994. The Location of Culture. London: Routledge.

Cifor, Marika. 2016. "Affecting Relations: Introducing Affect Theory to Archival Discourse". Archival Science 16 (1): 7-31 https://doi.org/10.1007/s10502-015-9261-5

Cvetkovich, Ann. 2003. An Archive of Feelings: Trauma, Sexuality, and Lesbian Public Cultures. Durham \& London: Duke University Press.

Dijck, Jose Van. 2007. Mediated Memories in the Digital Age. Stanford: University Press.

Edwards, Elizabeth. 2015. "Photographs as Strong History?", en Photo Archives and the Idea of Nation, editado por Constanza Caraffa y Tiziana Serena, 321-329. Munich, Berlin: Deutscher Kunstverlag.

Edwards, Elizabeth y Janice Hart. 2005a. "Introduction. Photographs as objects", en Photographs Objects Histories. On the Materiality of Images, editado por Elizabeth Edwards y Janice Hart, 1-15. London \& New York: Routledge.

Edwards, Elizabeth y Janice Hart. 2005b. "Mixed box: the cultural biography of a box 'ethnographic' photographs”, en Photographs Objects Histories. On the Mate- 
riality of Images, editado por Elizabeth Edwards y Janice Hart, 48-64. London \& New York: Routledge.

Enciclopedia histórica y biográfica de la Universidad de Guadalajara. S. a., s. v. "Vargas González, Ramón”.

http://enciclopedia.udg.mx/biografias/vargas-gonzalez-ramon

Latour, Bruno. 2008. Reensamblar lo Social: una introducción a la Teoría del Actor Red. Buenos Aires: Manantial.

Muriel, Daniel. 2013. "La construcción experta del patrimonio cultural." Tesis doctoral, Universidad del País Vasco.

Sekula, Allan. 2003. "Reading an archive: Photography between labor and capital", en The Photography Reader, editado por Liz Wells, 443-452. New York, Londres: Routledge.

Vaticano. S. a. José Anacleto González Flores y ocho compañeros. https://www.vatican.va/news_services/liturgy/saints/ns_lit_doc_20051120_ anacleto-gonzalez_sp.html

Willumson, Glenn. 2005. "Making meaning”, en Photographs Objects Histories. On the Materiality of Images, editado por Elizabeth Edwards y Janice Hart, 65-83. London \& New York: Routledge.

Zylinska, Joan. 2010. "On Bad Archives, Unruly Snappers and Liquid Photographs". Photographies 3 (2): 139-153.

https://doi.org/10.1080/17540763.2010.499608

Para citar este texto:

Peña Haro, Sandra. 2022. "Repensar el objeto fotográfico: un acercamiento desde la teoría del afecto". Investigación Bibliotecológica: archivonomía, bibliotecología e información 36 (90): 87-100.

http://dx.doi.org/10.22201/iibi.24488321xe.2022.90.58481 